\title{
The effects of the temperature on the mechanical properties of natural yarns
}

\author{
Y. Ben Smail' ${ }^{1}$ A. El Moumen², F. Lmai', A. Imad ${ }^{3}$ \\ 1. Energies renouvelables et dynamique des systèmes, Faculté des Sciences - Aïn Chock \\ , Casablanca, Maroc (y.bensmail@gmail.com, lmai.fatima@gmail.com) \\ 2. ENSTA Bretagne, IRDL - UMR CNRS 6027 Brest, France (ahmed.el_moumen@ensta-bretagne.fr). \\ 3. Unité de Mécanique de Lille, Université de Lille, France (abdellatif.imad@polytech-lille.fr)
}

\begin{abstract}
The jute fiber is one of the strongest lignocellulosic fibers with different applications such as fabrics, ropes as well as engineered composites for automobile parts. In this study, the jute yarns were exposed to different temperatures of the thermal cycles $\left(22^{\circ} \mathrm{C}, 40^{\circ} \mathrm{C}, 80^{\circ} \mathrm{C}\right.$, $105^{\circ} \mathrm{C}$ and $150^{\circ} \mathrm{C}$ ). The mechanical tests were conducted using the 3R Syntax machine and the experimental results depended on different temperatures of thermal cycles were recorded. The mechanical properties of jute yarns decrease with the increase of temperature of the thermal cycles.
\end{abstract}

Keywords: Jute fibers, Mechanical properties, Environmental degradation, thermal aging.

\section{Résumé}

La fibre de jute est l'une des fibres lignocellulosiques les plus solides avec des applications allant des articles simples tels que les tissus et les cordes aux composites techniques pour les pièces automobiles. Dans cette étude, les fils de jute sont exposés à des cycles thermiques de différentes températures $\left(22^{\circ} \mathrm{C}, 40^{\circ} \mathrm{C}, 80^{\circ} \mathrm{C}, 105^{\circ} \mathrm{C}\right.$ et $\left.150^{\circ} \mathrm{C}\right)$. Les tests mécaniques sont réalisés avec la machine 3R Syntx et les données expérimentales sont enregistrées pour les différentes températures des cycles thermiques. Les propriétés mécaniques des fils de jute diminuent en fonction de l'augmentation de la température des cycles thermiques.

Mots clefs: Fils de jute, Propriétés mécaniques, Dégradation de l'environnement, vieillissement thermique

\section{Introduction}

There has been an increasing interest of using natural fibers to replace glass fibers for composite reinforcement nowadays. The vegetable fibers present several advantages compared to synthetic fibers. They are biodegradable, lightweight and renewable, have good mechanical properties and are abundant. Furthermore, they are not abrasive to the processing equipment, have neutral emission of $\mathrm{CO}_{2}$ and are an important source of income for the population living in rural areas [1]. Compared to glass fibers, the production of natural fibers causes less environmental impacts. This is because the cultivation of natural fibers depends primarily on solar energy and needs small amount of energy from fossil fuels in the production and extraction processes. Jute fibers, comes from the stem and ribbon (outer skin) of the jute plant, will be the topic in this investigation. One of the main problems in the manufacturing of jute products resides in the optimization of yarn to use. The behaviour of jute fibers is controlled by two main parameters: the reorientation according to the loading axis of micro-fibrils and the slip of these latter ones according to the others. The micro-fibrils angle characterizing the jute is influenced by the percentage of cellulose in the jute which is more than $61 \%$. This microfibrils angle, generally about $8^{\circ}$, influences the mechanical behaviour of the jute. When this micro-fibrils angle is weak, the rigidity and the resistance of the fibre are higher, however, the adverse phenomenon is observed for elongation. These variations on the mechanicals properties of the jute fibers contributed to the dispersion of the properties of the jute yarns.

We performed the tensile tests using the jute yarns specimens, and, then, determined the tensile strength and modulus of elasticity of each specimen according to the temperature. We also studied thermo gravimetric analysis of jute yarns that were exposed to different temperatures of thermal cycles.

\section{Experimental Procedures}

\subsection{Tensile test}

The tensile test was performed in this study according to the ISO_6892 using the machine 3R Syntax with a $100 \mathrm{KN}$ load cell and a speed of $2 \mathrm{~mm} / \mathrm{min}$. 


\subsection{Material}

Jute is a bast fiber whose scientific name is Corchorus capsularis of Tiliaceae family. Plant of jute takes nearly 3 months to grow to a height of 12 - 15 feet. Jute plant is cut and kept immersed in the water for Retting process during season. The inner stem and outer gets separated and the outer plant gets individualized to form fibers. Jute fiber is known as golden fiber of Bangladesh, jute is an important fiber of Eastern Indian and Bangladesh [2]. The jute yarns are extracted from bi axial jute. This burlap intended to be impregnated in a thermosetting epoxy matrix to produce a composite plate.

\section{Results}

\subsection{Tensile tests.}

Figure 1 (a) represents the tensile curves of twenty five specimens of jute yarns. The results show a large dispersion of the properties of the jute yarns at the laboratory temperature of $22^{\circ} \mathrm{C}$. This dispersion can be attributed to firstly to the quality of the fibers and their properties and to the number of the continuous fibers in each specimen. The same behavior was found for all sets in this study, even if we expose the specimens to different temperature of the thermal cycles $\left(40^{\circ} \mathrm{C}, 80^{\circ} \mathrm{C}\right.$, $105^{\circ} \mathrm{C}$ and $150^{\circ} \mathrm{C}$ ) [3].

Figure 1 (b) shows the typical characteristic curve of the tensile test at the temperature $22^{\circ} \mathrm{C}$. The curve shows three distinguished parts before reaching the maximal stress. The first one on the onset of the curve is reserved to the alignments of the fibers. The second linear part can be considered as the elastic region of the curve. The third part is attributed to the elementary rupture of jute fibers [4].

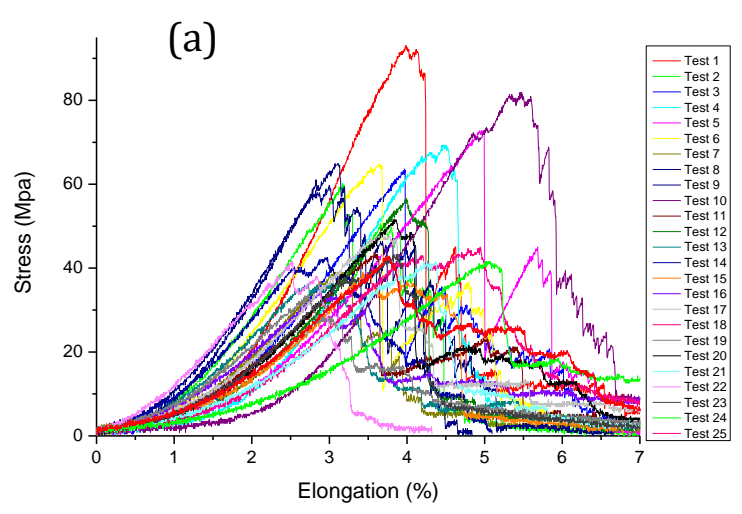

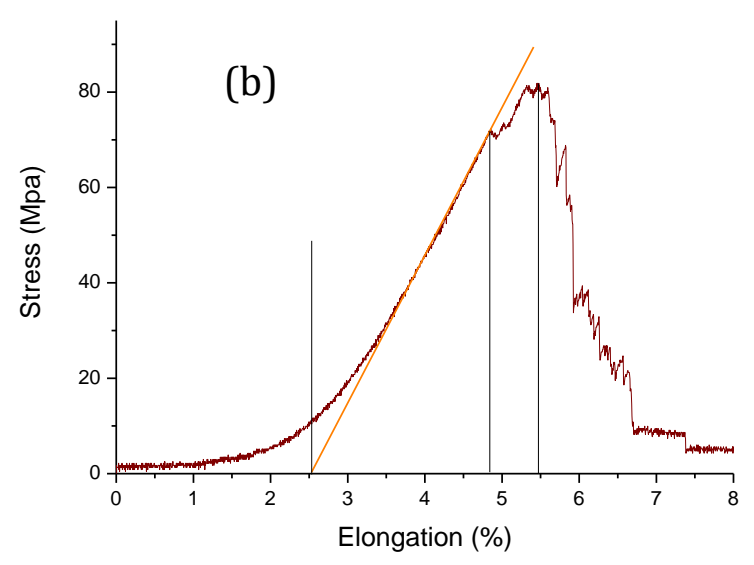

Figure 1: Stress-elongation curves: (a) twenty five samples tests and (b) tensile characteristic behavior of jute yarn in the laboratory temperature $\left(22^{\circ} \mathrm{C}\right)$.

The data Load-displacement curves found are analyzed to determine the material properties of jute yarns: tensile strength (TS), tensile modulus (E) and elongation at break. Firstly, the curves Load-displacement of the specimens of the jute yarns are converted into stresselongation curves. The equations used to do this are as follows:

$\varepsilon=\left(1-l_{0}\right) / 1$ and $\sigma=F /\left(\pi r^{2}\right)$ where $r$ is the radius of jute yarns. The maximum stress is considered as the tensile strength (TS) of the jute yarns. The elongation corresponding to TS is considered as the elongation to failure $\left(\varepsilon_{\mathrm{f}}\right)$. The tensile modulus $(\mathrm{E})$ of the jute yarns is determined as follows: $\mathrm{E}=\mathrm{TS} / \varepsilon_{\mathrm{f}}[6]$.

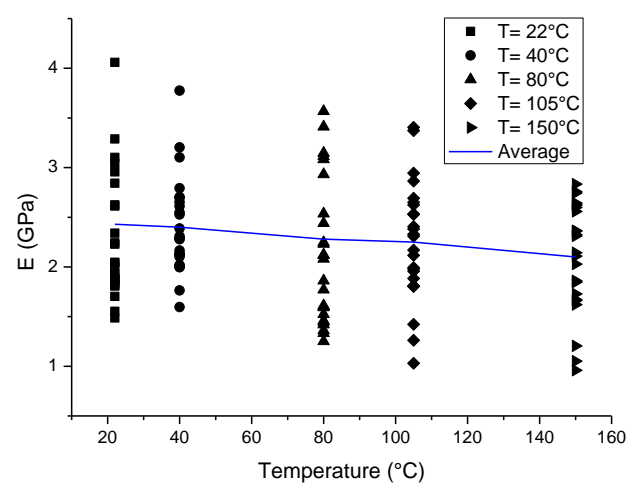

Figure 2: Tensile modulus variations according to temperature of thermal cycles of the jute yarns. 


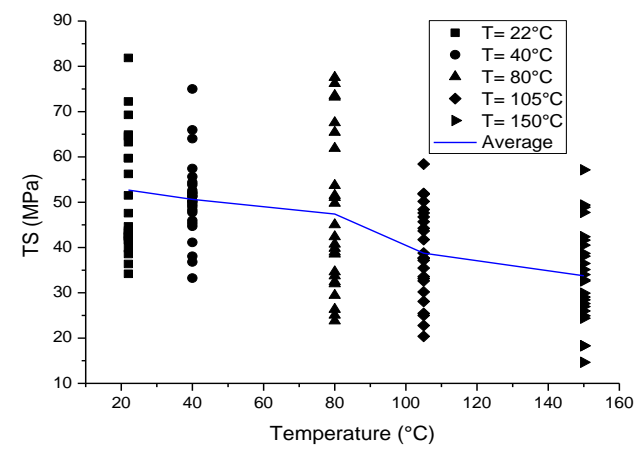

Figure 3: Tensile strength variations according to temperature of thermal cycles of the jute yarns.

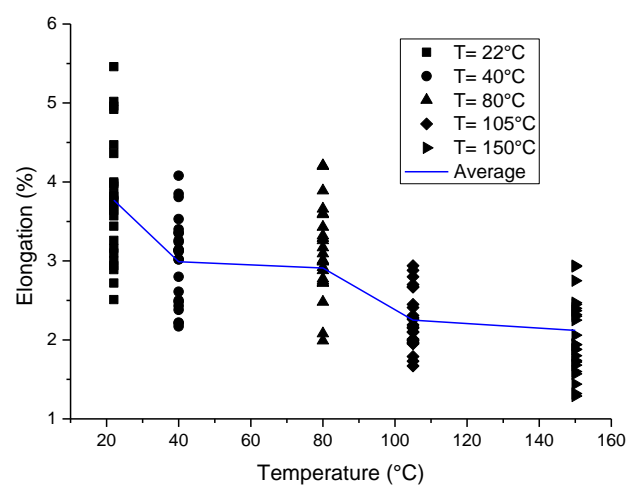

Figure 4: Elongation variations according to temperature of thermal cycles of the jute yarns.

Figure 2, Figure 3 and Figure 4 show the variations of the tensile modulus, tensile strength and elongation at break of jute yarns specimens at different temperatures of thermal cycles. The average tensile strength and elongation of the jute yarns decreases with increasing temperatures of the thermal cycles. This can be due to the decreases of the relationship between the matrix and the micro-fibrils of each fiber. This decrease of the cohesion is attributed to the damage created during the loss of humidity. For the average tensile modulus appears to be stable in various temperatures of the thermal cycles [6].

\subsection{Thermo gravimetric analysis.}

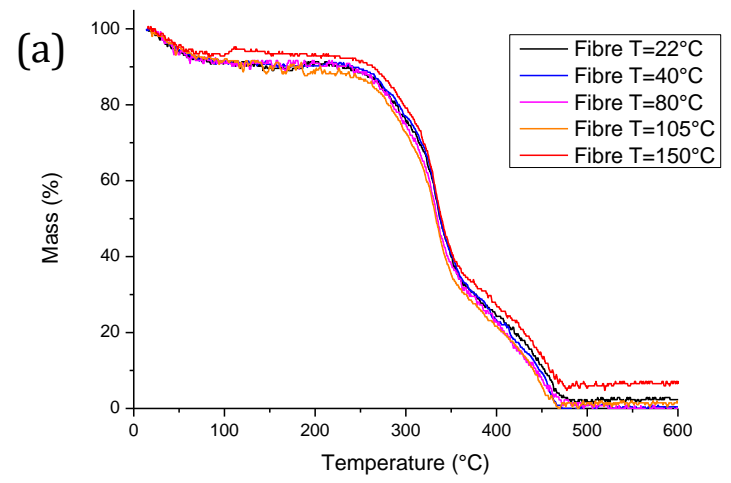

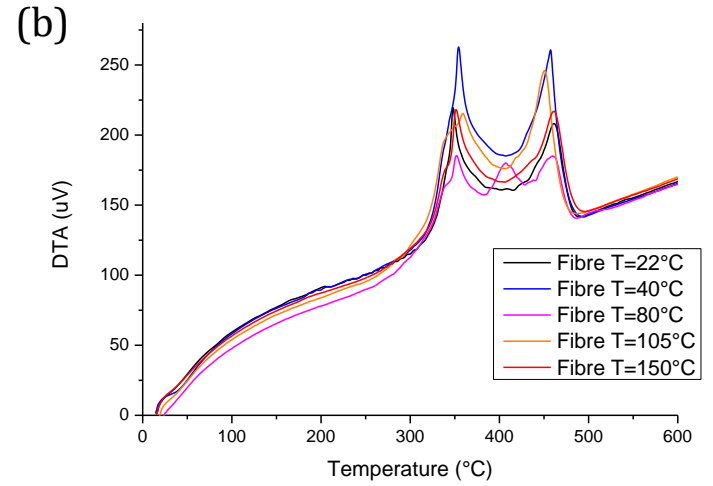

Figure 4: (a) TGA and (b) DTA curves.

Figure 4 (a) and (b) represent the thermo gravimetric analysis and DTA curves of jute yarns exposed to different thermal analysis temperatures. The results show that the jute yarns lose their capacity to reabsorbe the evaporated water on the onset of the curves. The curves show also an increase of the ash after temperature $600^{\circ} \mathrm{C}$ which explains the chemicals modifications inside the fibers at a high temperature.

\section{Conclusion}

The experimental study, conducted on specimens of jute yarn tested in tensile in various temperatures of thermal cycles, shows that the stress of the jute yarn decreases with increasing of the temperature, however; the elastic modulus is not affected by the thermal temperature. In addition, the jute yarns are anisotropic (high dispersion of results), confirming the work performed by other authors in the case of natural yarns [7]. The experimental results of the thermo gravimetric analysis emphasize the chemical modifications of the fibers exposed to high temperature thermal cycles.

\section{References}

[1] A. Sharif Ullah, On the Mechanical Properties and Uncertainties of Jute Yarns, Materials (2017), 10, 450.

[2] A. Belaadi, Mechanical properties of vegetal yarn: statistical approach, Composites Part B (2016), 09.033.

[3] B. Madsen, Hemp yarn reinforced composites I. Yarn characteristics, Composites: Part A 38 (2007) 2194-2203.

[4] S. Shahinur, Quantifying the uncertainty associated with the material properties of $a$ natural fiber, Procedia CIRP 61 ( 2017 ) 541 546.

[5] D. Xue, Mechanical properties of biaxial weftknitted flax composites, Materials and Design 46 (2013) 264-269.

[6] J. Moothoo, A study of the tensile behavior of flax tows and their potential for composite processing, Materials and Design 55 (2014) 764-772.

[7] M. R. Sanjay, Applications of Natural Fibers and Its Composites: An Overview, Natural Resources, 7 (2016) 108-114. 